\title{
ORKUT: UM ARQUIVO DIGITAL
}

\author{
Fabiana Parpinelli Gonçalves Fernandes \\ (Mestranda em Lingüística - UniFran) \\ Maria Regina Momesso de Oliveira
}

(Doutora em Lingüística - UNESP; Prof ${ }^{a}$ de Lingüística do Mestrado da UniFran)

Resumo: Entende-se arquivo como a lei que organiza a dispersão do discurso em conjuntos de "acontecimentos discursivos", ou seja, de "formações discursivas" (Foucault, 2005). O orkut, neste trabalho, é considerado um "arquivo digital", pois é definido como uma rede digital de relacionamento em que os discursos são regulados e organizados de acordo com o "jogo de relações de poder e saber" do grupo do qual se pertence. Assim, o presente artigo tem por objetivo refletir sobre a noção de arquivo (FOUCAULT, 2004) em suporte digital e ponderar acerca das práticas discursivas e subjetivadoras presentes em uma comunidade do orkut. O corpus de análise é um 'arquivo' digital que se constitui de uma comunidade do orkut intitulada "Tradutores/Intérpretes BR", formada por 7.845 membros, cuja finalidade é debater sobre a formação de profissionais e o mercado de trabalho. Para tanto, nosso gesto analítico pautase na análise de discurso pecheutiana; em noções foucautianas acerca das práticas discursivas, práticas de subjetivação e arquivo (1987, 2004, 2005); em autores que tratam das questões da modernidade líquida e das novas tecnologias e seus efeitos de sentido tais como Bauman $(1999,2001,2007)$ e Baudrillard (1981, 2005); e em Coracini (2007) no que tange à profissão do tradutor.

Palavras-chave: Análise do discurso. Arquivo. Sujeito. Tradutor. Orkut.

Abstract: Archive is understood as the law that organizes the dispersion of discourse in sets of "discursive events", that is, "discursive formations" (Foucault, 2005). Orkut, in this paper, is considered a "digital archive" as it is defined as a relationship digital network in which the discourses are regulated and organized in accordance with the "game of power-knowledge relation" of the group in which it belongs to. Thus, this paper aims of reflecting on the concept of archive (FOUCAULT, 2004) in digital support and on the discursive and subjectivation practices in an orkut community. The analysed corpus is a digital "archive" formed by an orkut community called "Tradutores/Intérpretes BR ", composed of 7845 members, which purpose is the discussion of the professional training and the labor market. For that, our analysis are based on Pêcheux's discourse analysis; on Foucault's notions about the discursive and subjectivation practices and archive (1987, 2004, 2005); on authors which deal with issues of liquid modernity and new technologies and their effects of meaning such as Bauman (1999, 2001, 2007) and Baudrillard (1981, 2005); and on Coracine (2007) about the profession of the translator.

Keywords: Discourse analysis. Archive. Subject. Translator. Orkut. 
Com o advento da Internet, o homem pôde reorganizar os mecanismos comunicacionais, favorecendo o surgimento de novas formas de articulações sociais, de informação e de cultura: e-mails, blogs, chats, youtube, orkut, msn, webcams, podcast, videologs, fotologs, second life, entre outras. Ao falarmos em novas tecnologias, é importante pensarmos nas novas formas de socialização e na constituição do sujeito por meio dos discursos que circulam dentro do espaço virtual. Podemos observar a presença das novas tecnologias em todas as atividades e práticas contemporâneas: "da mecânica à eletricidade, da microeletrônica, às nanotecnologias, a tecnologia propaga-se a uma enorme velocidade, infiltrando-se tanto em objetos do quotidiano como no corpo humano" (LEMOS, 2004, p.21).

$\mathrm{O}$ autor também afirma que as novas tecnologias vêm se misturando ao nosso ambiente cultural de forma quase imperceptível, aproximando a "tecnologia contemporânea do prazer estético e do compartilhamento social" (LEMOS, 2004. p.21 ). Como exemplo da aproximação do prazer estético e do compartilhamento social, podemos mencionar o orkut, com seus inúmeros perfis e comunidades, que favorece um "novo" "[1] processo de produção e circulação de discursos e efeitos de sentidos e que necessita de estudos aprofundados para a compreensão de como se dá a construção da identidade do sujeito nas novas tecnologias.

O orkut, uma das principais redes ${ }^{[2]}$ digitais de socialização ${ }^{[3]}$ do século XXI, tem por objetivo viabilizar as relações sociais envolvidas em ambiente virtual. Ele é composto por duas partes: as páginas pessoais dos usuários e as comunidades. A página pessoal é formada pelo perfil do usuário, que disponibiliza fotos, arquivos de vídeos, depoimentos, recados, eventos e algumas informações particulares divididas em três categorias - social, profissional e pessoal - e que podem ser acessadas e visualizadas por todos os membros do orkut.

As comunidades funcionam como grandes fóruns de discussão de assuntos diversos, possuem uma imagem ou foto geralmente relacionada com o seu tema e um texto que descreve seus objetivos e propósitos. Elas são formadas pelo "fórum", onde os membros discutem o assunto proposto em cada tópico; por "enquetes", cujo objetivo é colher opiniões dos seus membros de forma quantitativa; por "eventos", um espaço de divulgação de cursos e encontros; e por uma listagem de todos os "membros" que as compõem. O usuário do orkut pode ingressar em qualquer comunidade, desde que aceito pelo mediador quando moderada por este, bem como se desvincular delas quando desejar.

Nesse espaço digital, o indivíduo se (re)constrói como sujeito ou sujeitos por meio de suas práticas discursivas projetando sua subjetividade de forma real ou imaginária. Porém, os efeitos e conseqüências dessa interação do 
indivíduo no mundo digital ainda são pouco conhecidos.

Por essa razão, este artigo pretende refletir sobre a noção de arquivo diante das novas tecnologias de informação (redes digitais de socialização) e ponderar acerca das práticas discursivas e subjetivadoras presentes na comunidade d o orkut Tradutores/Intérpretes BR. Para tanto, tomamos como corpus de análise um "arquivo" digital que se constitui da maior comunidade de tradutores e intérpretes do orkut, intitulada Tradutores/Intérpretes $\mathrm{BR}^{[5]}$, cuja finalidade é debater sobre a formação de profissionais e o mercado de trabalho. É importante ressaltar que essa comunidade é formada por 7.845 membros ${ }^{[6]} \mathrm{e}$ que seu número cresce a cada nova consulta.

Para nortear nossa reflexão, foi escolhida como fundamentação teórica a análise do discurso francesa (AD), fundada por Michel Pêcheux no ano de 1969; as idéias de Michel Foucault acerca das questões de práticas discursivas, de práticas de subjetivação e sua concepção de arquivo (1987, 2004, 2005); em Bauman $(1999,2001$; 2007) e Baudrillard $(1981,2005)$, buscamos as questões sobre identidade e modernidade líquida; em Coracini (2007), as questões sobre as atividades e a profissão do tradutor; e em autores que puderam contribuir com as reflexões sobre pós-modernidade, novas tecnologias e seus efeitos de sentido.

\section{Orkut: rede digital de socialização}

O orkut é uma rede digital de socialização, filiada ao Google, com o objetivo de viabilizar as relações sociais envolvidas em ambiente virtual. É uma rede para comunicação entre amigos ou para aqueles que buscam novos relacionamentos, conforme divulgado pelo próprio site do orkut em seu texto de apresentação:

O orkut é uma comunidade on-line criada para tornar a sua vida social e a de seus amigos mais ativa e estimulante. A rede social do orkut pode ajudá-lo a manter contato com seus amigos atuais por meio de fotos e mensagens, e a conhecer mais pessoas. Com o orkut é fácil conhecer pessoas que tenham os mesmoshobbies e interesses que você, que estejam procurando um relacionamento afetivo ou contatos profissionais. Você também pode criar comunidades on-line ou participar de várias delas para discutir eventos atuais, reencontrar antigos amigos da escola ou até mesmo trocar receitas favoritas. Você decide com quem quer interagir. Antes de conhecer uma pessoa no orkut, você pode ler seu perfil e ver como ela está conectada a você através da rede de amigos. Para ingressar no orkut, acesse a sua Conta do Google e comece a criar seu perfil imediatamente. Se você ainda não tiver uma Conta do Google, nós o ajudaremos a criá-la em alguns minutos. Nossa missão é ajudá-lo a criar uma rede de amigos mais íntimos e chegados. Esperamos que em breve você esteja curtindo mais a sua vida social. (Disponível em: <http://www.orkut.com/About.aspx>. Acesso em: 20 jul. 2008.).

Tal rede de socialização foi criada em 22 de Janeiro de 2004, pelo engenheiro e projetista turco Orkut Büyükkokten ${ }^{[7]}$, durante os $20 \%$ da jornada 
de trabalho que a empresa Google disponibiliza a seus funcionários para realizarem atividades relacionadas a algum projeto pessoal (NOGUEIRA, 2004). Quando algum desses projetos é aprovado e implementado na empresa, seu autor ganha um prêmio chamado "Founders" que funciona como um incentivo ao funcionário criativo e inovador.

A criação do orkut deu-se em razão da dificuldade que os calouros da Stanford University tinham em fazer novas amizades, pois, segundo seu próprio criador, os amigos eram feitos apenas no primeiro ano universitário e mantidos até se formarem. Em uma palestra realizada no Brasil ${ }^{[8]}$, Orkut justificou esta dificuldade afirmando que, "[...] se você puxa conversa com uma menina, ela acha que você está cantando ela; se você fala com um cara, ele acha que você é gay!".

Em 2001, Orkut criou sua primeira rede de relacionamentos, a Club Nexus, para alunos da Stanford University. Em 2002, criou outra rede para ex-alunos dessa mesma universidade, a InCircle. Em 2004, já trabalhando no Google, lançou o orkut, com o intuito de ser uma rede globalizada, ao alcance das pessoas do mundo inteiro, mas sem a pretensão de que se tornasse uma das maiores redes digitais de socialização mundialmente conhecida.

Atualmente, o orkut possui mais de sessenta e oito milhões de usuários cadastrados que ingressam na rede por meio da criação de uma conta no Google . O número de usuários cresce a cada nova consulta, porém não representa precisão, já que muitos membros criam mais de um perfil por usuário, os chamados fakes, ou perfis falsos, ou são menores de 18 anos $\stackrel{[10]}{\text { que }}$ mentem sua idade ao completar seus perfis sem serem identificados. Tais práticas são condenadas pela política do site.

Um fato interessante quanto à colocação de informações falsas, foi quando do boato dizendo que o usuário que se declarasse ser de um outro país, que não o Brasil, obteria um sistema mais rápido e livre de erros. Dessa forma, muitos usuários brasileiros declararam residir em outros países, o que torna, conseqüentemente, os dados estatísticos sobre o orkut imprecisos.

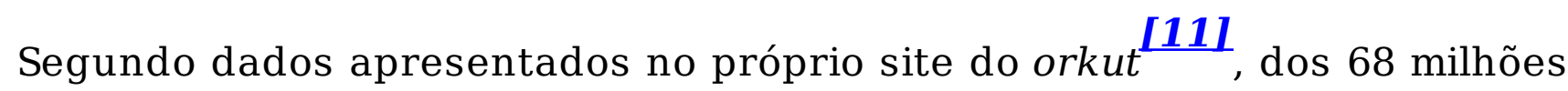
de usuários que participam dessa grande rede digital de relacionamento, o Brasil é o país com o maior número de membros $(51,19 \%)$, superando inclusive os EUA (17,60\%), seu país de origem, que ocupa o segundo lugar em número de usuários. Esse fato resultou na criação de uma versão brasileira do orkut em abril de 2005. Em terceiro e quarto lugares estão a Índia (17,34\%) e o Paquistão (1,02\%), respectivamente. Outros países como o Reino Unido, Afeganistão, Japão, Portugal, Alemanha e Austrália foram apresentados nos dados, porém, representam um percentual inferior a $0,50 \%$.

Se considerarmos uma pesquisa realizada em 2007 pelo Núcleo de 
Pesquisa, Estudos e Formação (Nupef) $\stackrel{[12]}{ }$ apontando que apenas $20 \%$ dos brasileiros têm acesso à Internet, enquanto mais da metade da população americana o possui, podemos concluir que o brasileiro aprecia o fácil acesso às informações sobre outras pessoas, que tem facilidade em adaptar-se às novas tecnologias e que gosta de fazer novas amizades, mesmo que de forma virtual.

O próprio criador do orkut, ao ser entrevistado pela Folha Online $\stackrel{[13]}{\text {, após }}$ sua chegada ao Brasil em 2005, diz não ter idéia sobre o motivo da presença maciça de brasileiros em seu site de relacionamentos:

Talvez seja cultural, tenha a ver com a personalidade de vocês, que são conhecidos como um povo amigável. Pode ser devido à própria característica do mecanismo de entrada no site (só pode se cadastrar quem receber um convite de um dos cadastrados). Eu tenho alguns amigos que têm amigos brasileiros, e assim foi se espalhando, o que era mesmo a minha idéia desde o início. (FOLHA ONLINE, 03 jul. 2005).

Beth Saad, professora de Mídias Digitais da Escola de Comunicação e Artes da Universidade de São Paulo, justifica a grande presença de brasileiros na rede: "o brasileiro tem um espírito gregário, quer a casa cheia de amigos. No orkut, faz a mesma coisa: convida o maior número de amigos possível". (NOGUEIRA; TERMERO; LEAL, 2004, p. 98)

O site do orkut também oferece outros dados estatísticos relacionados ao perfil do usuário: faixa etária, estado civil e interesse dos usuários $\stackrel{[14]}{\text {. Como }}$ mencionado anteriormente, os dados apresentados não representam exatidão, o que torna impossível traçar o perfil do usuário do orkut por meio do simples levantamento de dados oferecidos pelo próprio site. O resultado final daria margem a dúvidas e erros impossíveis de serem averiguados.

O orkut funciona como um grande banco de dados onde as informações que ali se encontram podem ser acessadas e visualizadas por todos os seus membros. Apesar da Internet se propor como um meio democrático, dinâmico e ágil, ao se cadastrar no orkut, todos os dados pessoais do usuário passam a ser controlados pelo Google. Segundo Cebrián (1999, p. 88):

O rastro que as comunicações nos servidores de acesso deixam é absoluto. Nosso correio eletrônico pode ser lido impunemente. [...] As leis de proteção de dados e outras similares, que tratam de assimilar o bom uso dos registros informatizados, sejam privados ou oficiais, não costumam levar em conta essa situação. O paradoxo é que um sistema que presume ser participativo, universal e aberto, oferece também a possibilidade de um controle quase total dos cidadãos.

Sobre a questão da privacidade, a Revista Super Interessante, de setembro de 2004, afirmou que "no orkut, todos os usuários têm acesso a dados pessoais dos outros e todo mundo sabe quem é amigo de quem. Privacidade definitivamente não é prioridade por lá". (NOGUEIRA, 2004, p.87)

Bauman (2001, p.16) afirma que vivemos a era do sinóptico, em que muitos 
observam poucos, ao contrário da era do panóptico, em que poucos observavam muitos. O orkut, com seus perfis e comunidades virtuais, é um exemplo desse sinóptico de observação de múltiplos olhares sobre o indivíduo.

Os principais problemas relacionados ao orkut não estão ligados ao site em si, mas aos danos causados pelas informações que ali circulam: usuários que agem de má fé, falsos perfis (fakes) e divulgação de comunidades ilegais (apoio à pedofilia, crimes digitais, falsidade ideológica, calúnia, difamação, injúria, racismo, neonazismo, intolerância religiosa, venda de drogas e receitas médicas, incitação ao crime, formação de quadrilha, entre tantos outros).

Em março de 2006, o Ministério Público de São Paulo pediu à Justiça Federal a quebra de sigilo de centenas de usuários brasileiros do orkut em razão de informações sobre crimes praticados dentro do serviço do Google, sendo eles: pornografia infantil, ódio racial, venda de drogas e de medicamentos sem receitas.

Segundo o GARRA (Grupo Armado de Repressão a Roubos e Assaltos), uma das divisões de elite da Polícia Civil do Estado de São Paulo, alguns seqüestros no Brasil já foram realizados com a ajuda de dados obtidos no próprio orkut: os bandidos apropriam-se de dados e fotos das eventuais vítimas disponibilizados em seu perfil, estudam os ambientes que elas freqüentam, monitoram conversas via scraps (mensagens trocadas pelos usuários), estudam o círculo social e padrão de vida a fim de planejarem seqüestros e falsos seqüestros.

Grande parte dos usuários do orkut não tem consciência de que fazem parte de um grande banco de dados e de que o ambiente digital é tão controlador quanto o real, e muitas vezes mais perigoso.

Independente das questões de privacidade, vigilância e segurança, o número de usuários que utiliza o orkut cresce a cada dia, pois seus membros têm o intuito de reencontrar amigos, ampliar o círculo social, criar redes de interesses. Cresce também o número de sites semelhantes ao orkut, como é o caso do Beltrano, Gazzag, Hi5, Peepow, Multiply, Universe, entre tantos outros.

Um dos fatores que contribuíram para a explosão dessas redes digitais de socialização em todo o mundo, e principalmente do orkut entre os brasileiros, refere-se à facilidade em seu manuseio. Elas são extremamente amigáveis aos usuários, ou seja, fáceis de serem criadas e usadas. Soma-se a isso o livre acesso ao perfil de todos os usuários, o gerenciamento de seus contatos, a autonomia para criar, aderir ou excluir-se de qualquer comunidade, de fato, facilidades que se tornam sedutoras ao usuário.

Podemos observar que as novas tecnologias afetam a sociedade em que vivemos, interferindo não só na maneira como vemos o mundo, mas também como dele participamos. Desta forma, o orkut é uma rede digital de socialização que (re)cria discursos e subjetividades cujos efeitos de sentido ainda são pouco conhecidos. Além disso, constitui-se em um grande banco de dados, em um arquivo digital que cria leis de convivência, de identificação, e que traça 'novas' 
formas de ser, ver e observar o indivíduo.

\section{Arquivo e rede digital}

Um dos teóricos que fornece campo apropriado para nossos estudos é Michel Foucault. O filósofo francês abriu um leque fascinante de inúmeras investigações envolvendo questões sobre os saberes, o sujeito, o processo de subjetividade, a loucura, o poder, a sexualidade. Diante dessa multiplicidade de olhares, é possível buscar interpretações para um grande número de investigações, porém, esta mesma multiplicidade torna esse autor impossível de ser caracterizado como representante de uma única episteme. Nossa escolha por esse filósofo deve-se ao fato do sujeito ter sido o foco de suas investigações, mesmo que nem sempre de forma consciente em todos os seus trabalhos.

E m Arqueologia do Saber (2004), publicado em 1969, Foucault explica teórica e metodologicamente o método arqueológico que já havia sido mencionado em obras anteriores como $O$ nascimento da clínica: a arqueologia do saber médico de 1963 (2004a) e As palavras e as coisas: a arqueologia das ciências humanas (1987), publicado em 1966, mas, cujo significado, segundo o próprio autor, "tinha deixado vazio" (FOUCAULT apud GREGOLIN, 2007, p. 91).

A arqueologia foi, até o final da década de 1970, o método que marcou as pesquisas de Foucault e, posteriormente, o termo passou a ser chamado de genealogia ${ }^{[15]}$, duas terminologias não só complementares, mas inseparáveis. Devido à ambigüidade da palavra "arqueologia", Foucault recusa dois sentidos que podem ser associados a ela: "busca da origem" e "escavação de significados secretos" (GREGOLIN, 2007, p. 82).

O objeto de estudo do método arqueológico é o saber de uma época, buscando-se compreender as condições histórico-sociais que possibilitaram a irrupção de acontecimentos discursivos no interior de um mesmo arquivo e o aparecimento de determinados enunciados e não outros em seu lugar.

O acontecimento discursivo, segundo Gregolin (2007, p.83), apesar de possuir uma irrupção brutal, "obedece a uma combinação de regras, que constituem o arquivo, e que determinam as condições de possibilidades de sua aparição".

Foucault (2004, p. 148-149) explica, em A Arqueologia do Saber, o que considera ser um arquivo:

[...] a lei do que pode ser dito, o sistema que rege o aparecimento dos enunciados como acontecimentos singulares. Mas o arquivo é, também, o que faz com que todas as coisas ditas não se acumulem indefinidamente em uma massa amorfa, não se inscrevam, tampouco, em uma linearidade sem ruptura e não desapareçam ao simples acaso de acidentes externos, mas que se agrupem em figuras distintas, se componham umas com as outras segundo relações múltiplas [...].

O conceito de arquivo de Foucault (2004) reformulou a maneira de 
organizar os corpus a serem analisados, visto que antes, nos estudos da História, eram privilegiados em sua forma linear e cronológica e agora são organizados a partir de uma diversidade de textos, de um trajeto temático e de um acontecimento discursivo.

Opondo-se aos estudos da História tradicional, em que o pesquisador busca encontrar relações de causalidade nos documentos do passado, Foucault, pelo método arqueológico, propõe ao pesquisador transformar o documento da história em monumento, descobrindo suas especificidades e a lei que os rege. Portanto, Foucault propõe não uma análise que busque o emparelhamento dos textos e suas regularidades, pelo contrário, ele deseja romper o fio da continuidade e buscar o descontínuo, as brechas, a especificidade que é preservada em cada texto.

Mandarin (1979 apud SARGENTINI, 2004, p. 88), partindo de Foucault, afirma que "o conjunto de enunciados constitui o arquivo de uma época. Este conjunto não é a coleção de um espaço homogêneo [...] mas um conjunto de regiões heterogêneas de enunciados produzidos por práticas discursivas irredutíveis".

O próprio Foucault (2004, p.149) afirma que o arquivo não é o que recolhe a poeira dos enunciados que novamente se tornaram inertes e que permite o milagre eventual de sua ressureição; é o que define o modo de atualidade do enunciado-coisa; é o sistema de seu funcionamento. Também não é o que unifica tudo o que foi dito no grande murmúrio confuso de um discurso, nem o que nos assegura a existência no meio do discurso mantido, mas sim, o que diferencia os discursos em sua existência múltipla e os especificam em sua duração própria.

O orkut constitui-se em uma existência múltipla porque traz ao mesmo tempo os 'velhos' discursos de amizade característicos dos diários, da correspondência entre amigos, e os 'novos' que circulam em uma ambiente

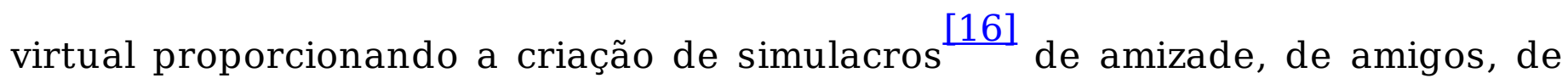
profissionais, entre outros.

Gregolin (2007, p.98) afirma que na obra A Arqueologia do Saber, Foucault une todos os conceitos por ele estudados: "enunciado, formações discursivas; conjunto de enunciados (discurso); práticas discursivas; a priori histórico; positividade; arquivo". Foucault parte da concepção de enunciado para a de arquivo e, o discurso, conceito central da investigação arqueológica, passa a ser situado entre a estrutura e o acontecimento, pois, de um lado temos as regras da língua e de outro, aquilo que é efetivamente dito.

Outros autores que também refletiram sobre o conceito de arquivo, após 20 anos de estudos em Análise do Discurso, foram: Guilhaumou \& Maldidier (1994, p.164):

$\mathrm{Na}$ perspectiva atual, consideramos a complexidade do fato arquivista. O arquivo nunca é dado a priori, e em uma primeira leitura, seu funcionamento é opaco. Todo arquivo, principalmente manuscrito, é identificado pela presença de uma 
data, de um nome próprio, de uma chancela institucional, ou ainda pelo lugar que ele ocupa em uma série. Essa identificação, puramente institucional, é para nós insuficiente: ela diz pouco do funcionamento do arquivo. Nossa prática atual de análise do discurso retoma as preocupações dos historiadores de mentalidades, que na construção de objetos como a morte, o medo, o amor, o profano e o sagrado, instalam pela confrontação de séries arquivistas, regimes múltiplos de produção, circulação e leitura de texto.

Analisar discursos baseado nas concepções de Foucault sobre arquivo implica buscar os enunciados não interrompendo a sua trajetória, mas buscá-los em suas movências. Por movências, entende-se, de acordo com Gregolin (2004, p. 36), "a movimentação dos enunciados [...] nos atos praticados por sujeitos historicamente determinados".

E, para que os enunciados sejam analisados como pertencentes a um mesmo discurso, Foucault (apud GREGOLIN, 2007, p.107-108) propõe quatro critérios de análise:

\begin{abstract}
“a) os enunciados devem estar relacionados a um mesmo domínio de objetos; b) os enunciados devem ser originados por uma mesma modalidade de enunciação [...]; c) um discurso será individualizado pelas escolhas e estratégias de argumentação que mobiliza; d) cada discurso define uma diferente função para o sujeito, isto é, define estatutos, posições que o sujeito pode ocupar".
\end{abstract}

Entretanto, Foucault não busca encontrar nos discursos a atividade consciente do sujeito, ou seja, aquilo que ele teve intenção de falar. Pelo contrário, a arqueologia busca interrogar "as condições que propiciaram o aparecimento de um determinado enunciado e não outro em seu lugar" (NAVARRO-BARBOSA, 2004, p.111).

Essas reflexões nos fazem crer que os discursos encontrados na comunidade Tradutores/Intérpretes BR inscrevem-se em um mesmo arquivo, ou seja, no interior de uma mesma formação discursiva, pois surgiram em função de "um jogo de relações" e de "regularidades específicas" (FOUCAULT, 1987, p, 149), o que os torna passíveis de investigação neste artigo.

Navarro-Barbosa (2004, p.116), em seu trabalho sobre $O$ acontecimento discursivo e a construção da identidade na História, afirma que "a nossa sociedade dispõe de um arquivo sobre o que é ser brasileiro, negro, escravo, índio, sobre a nossa constituição como colônia e depois como nação, sobre nossa natureza". Por meio deste arquivo, é possível observar o que "a nossa sociedade pode dizer de si mesma" (Ibid, 2004, p.116).

Podemos afirmar que o mesmo ocorre com a comunidade do orkut Tradutores/Intérpretes BR que, ao ser analisada às luzes da AD (PÊCHEUX, 2006) e dos pressupostos teóricos foucaultianos (1987, 2004, 2005), apresentanos um arquivo sobre o que é ser um sujeito tradutor e intérprete nos tempos da modernidade líquida $\stackrel{[17]}{\text {. }}$

$\mathrm{O}$ arquivo digital da comunidade Tradutores/Intérpretes BR apresenta-se como um espaço libertário do dizer sobre o profissional Tradutor/Intérprete. 
Nesse espaço encontra-se, na realidade, um banco de dados sobre seus membros: local onde trabalham; queixas sobre a profissão; valor cobrado por palavra traduzida; motivo da escolha profissional; formação profissional.

As questões relativas à formação do banco de dados são realizadas em formato de enquete e sugerem de quatro a cinco respostas, como por exemplo, sobre "o local de trabalho" $[18]$ apresentando as seguintes opções: a) em casa ou em escritório próprio; b) em uma agência de tradução; c) em uma empresa, na área de tradução e d) outros. Especifique.

Como resultado, temos $93 \%$ dos membros da comunidade executando sua tarefa de tradução em casa ou em escritório próprio. Na enquete sobre "o que mais incomoda os membros dessa comunidade" oferta de serviço (43\%), o mercado 'mal-educado' (24\%), e a concorrência (4\%).

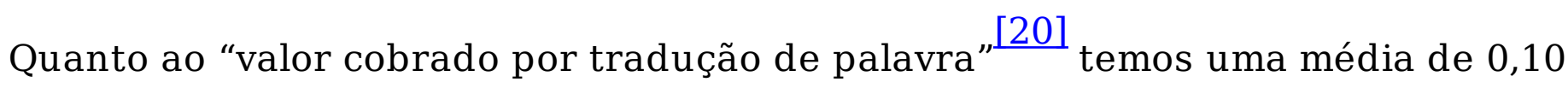
a 0,30 centavos de real. No porquê da "escolha da profissão" gosto pelo aprendizado de línguas estrangeiras; $20 \%$ oportunidade surgida na área de trabalho/estudos; $12 \%$ bilingüismo por descendência ou vida no exterior; $3 \%$ por influência de outro tradutor (amigo, familiar...) e 12\% outro.

Podemos perceber que o arquivo digital agrega as informações sobre os tradutores da contemporaneidade. Assim, os discursos existentes nesse arquivo mostram um perfil de profissional inserido no mundo globalizado, a começar pelo local de trabalho que antes estava geralmente estabelecido em uma instituição com horários de entrada e saída, hoje, se trabalha em casa ou em seu próprio escritório o que pressupõe que o profissional faz seu próprio horário. Ressalta também o medo pela oscilação de serviço de tradução - uma vez autônomo, o tradutor recebe por aquilo que produz e não por salário mensal.

Tudo isso mostra que o usuário dessa comunidade procura apresentar-se com um novo perfil do profissional de tradução adequado à sociedade globalizada e das novas tecnologias. Pois, além de ter qualificação profissional, possui envolvimento emocional e social, conhece seu mercado de trabalho e, portanto, discute sobre ele. Sabe potencializar a comunicação, a interpretação de dados, a flexibilização, a integração funcional e a geração, absorção e troca de conhecimento. Portanto, um indivíduo capaz de operacionalizar seu conhecimento profissional de modo integrado às suas aptidões e vivências socioculturais, quesitos básicos dos solicitados pela contemporaneidade.

Conforme Sargentini (2004, p. 91) afirmou: "o arquivo passa a ser, então, um lugar para se pensar as práticas discursivas de uma sociedade".

\section{As práticas discursivas e identitárias na comunidade Tradutores/Intérpretes BR}


O número de comunidades no orkut é imenso, bem como a diversidade de assuntos abordados. Ao fazermos uma busca no orkut por comunidades cujo assunto é "tradução" obtivemos um resultado de 754 comunidades. Em uma segunda busca com o assunto "tradutor" e, posteriormente, "tradutores", chegamos, respectivamente, a 113 e 69 comunidades. Dessa forma, para a análise proposta neste artigo, foi necessário escolher uma entre tantas comunidades disponíveis.

Depois de termos visitado e analisado diversas comunidades que tinham como assunto central a tradução, observamos que seus objetivos também eram diversos, tais como: comunidades de tradução juramentada, de textos religiosos, de audiovisual (dublagem e legendagem), de músicas, literária, científica, de RPG, de Mangás, dos livros do Harry Potter, ferramentas de auxílio ao tradutor, estudos da tradução, protestos a traduções mal feitas, além de tradutores vinculados a instituições de ensino superior.

Com tantas opções de escolha, optamos pela comunidade intitulada Tradutores/Intérpretes BR, por ser a maior comunidade de tradução encontrada no orkut, formada por 7.845 membros, e por ser uma comunidade de tradutores e intérpretes brasileiros que trabalham com a língua portuguesa (do Brasil) como uma de suas línguas (fonte ou alvo), cuja finalidade, apresentada no próprio site, é "debater sobre a formação de profissionais, cursos, mercado de trabalho, ferramentas, terminologia, remuneração, teoria, entre outros assuntos". Criada em 30 de abril de 2004, é uma comunidade moderada, ou seja, seu conteúdo é controlado por um mediador e não permite a postagem de mensagens anônimas. Nela é permitido que clientes solicitem a prestação de serviços de tradução/interpretação, desde que remunerados, porém, não é permitido que tradutores ofereçam seus serviços.

Analisamos os dados coletados na perspectiva metodológica do trajeto temático, e, para isso, foi escolhido um tema que nos pareceu mais significativo para a prática profissional desses sujeitos: a questão da formação acadêmica em oposição à formação não acadêmica, pois uma vez que a área de tradução e interpretação não é regulamentada $\stackrel{[22]}{ }$, inúmeros debates sobre a necessidade ou não de formação acadêmica são gerados entre os tradutores na comunidade analisada, tornando esse tema recorrente.

Entre os assuntos discutidos pelos membros da comunidade e que dizem respeito ao trajeto temático escolhido, podemos citar os seguintes:

1. No fórum de discussão: "opiniões sobre as faculdades públicas de tradução", "o poder do diploma", "aspirantes a tradutor", "para tradutores novatos e candidatos à tradução";

2. Nas enquetes: "grau de escolaridade", "a tradução é a sua atividade profissional principal?", "qual sua formação em tradução?";

3. Nas FAQS ${ }^{\lfloor\mathbf{2 3 I}}$ : quem tem curso superior de tradução?”, 
"regulamentação", "faculdade", "por favor, recomendem cursos", "filiações e credenciamentos".

Ao analisarmos o discurso produzido pelos tradutores e intérpretes na comunidade selecionada, observamos que o mesmo (o discurso) parte de diversos lugares enunciativos (academia, editoras, agências de tradução, informalidade) e mostra a angústia em definir quem é o sujeito profissional tradutor/intérprete pertencente à modernidade líquida.

Baseando-se na perspectiva do trajeto temático escolhido, podemos observar um confronto de dois lugares enunciativos (formação acadêmica $\mathrm{x}$ formação não acadêmica) em uma discussão intitulada "opiniões sobre as faculdades públicas de tradução," ${ }^{[24]}$ de 15 de setembro de 2007:

Sujeito 1: “Bom, eu sou aluno de tradução na (nome da instituição) e estou cursando o quarto semestre. Estou pensando em mudar de (nome da cidade) e pedir transferência, [...] Então, vocês podem me dizer quais faculdades públicas estão oferecendo o curso, e como está a qualidade do ensino delas...? Obrigado".

Sujeito 2: “Não fiz faculdade de Tradução, mas fiz de Letras [...] Quando entrei no primeiro ano, o pessoal do quinto já me passava as provas que eu ia fazer quando chegasse no quinto ano. [...] Quer dizer, esse negócio de faculdade e qualidade não muda assim em pouco tempo. [...] Mas por favor, não me leve a mal - não estou querendo impedir discussão nenhuma, muito menos o seu direito de querer informações atualizadas. Elefantas, já leu as FAQs? Tem muita coisa boa lá. :)"

Sujeito 1: "Sim, li de cabo a rabo, heheheh. E bom, mesmo nas FAQs, não tem nenhuma informação organizada quanto à qualidade, opiniões, aceitação de mercado e conceito geral das públicas que oferecem Tradução."

Sujeito 3: "A maior parte do mercado não dá a mais remota atenção à faculdade que você fez ou se fez alguma faculdade. Os clientes sérios vão te pedir um teste, talvez entrevistar, fazer perguntas. Se você se sair bem, ótimo. Se você se sair mal, azar seu. Os clientes que não são sérios vão simplesmente pegar quem cobre mais barato. [...]. A (nome) estudou, aprendeu, tem futuro. Bom, os outros, os espertinhos, vão ter que se virar."

Sujeito 4: "Muito prazer e bem vindo à comunidade. Não sou formada em Tradução. Assim como a (nome), fiz somente letras. Meu pitaco sobre os melhores lugares para se aprender sobre tradução, softwares, bibliografias, o que esperar da profissão, é aqui nesta comunidade, no blog do (nome), que tem imensa experiência e gratuitamente compartilha conosco, na reunião na sala da Aula Vox [...] Todos aqui ajudam com prazer e é uma riqueza sem fim, o que se aprende por aqui. [...] Boa sorte e lembre-se, a cidade do tradutor é o mundo!!!”

Sujeito 5: "Sou formada em tradução e interpretação pela (nome da instituição) e isso foi fundamental para o meu ingresso no mercado de trabalho além de muito esforço, paciência, dedicação e disciplina."

E m A ordem do Discurso (2005), Foucault analisa os procedimentos que permitem o controle do discurso, ou seja, "quem fala", o "lugar da fala" e "as posições do sujeito". É por meio da análise destas práticas discursivas que a dispersão do sujeito aparece.

Os discursos dos tradutores e intérpretes, até então presentes apenas em artigos publicados em periódicos, revistas especializadas sobre tradução, prefácios de obras traduzidas, bem como textos sobre tradução, agora passam a ser encontrados em ambientes digitais, como na comunidade analisada. 
Entretanto, esses discursos, sejam eles tradicionais ou tecnológicos, manifestam uma memória discursiva, resultados de discursos já institucionalizados por um determinado grupo que está no poder ou pelo próprio sistema.

Segundo Foucault (1987), o discurso não é pura e simplesmente entrecruzamento de palavras e coisas, nem trama obscura das coisas em palavras e, muito menos, a estreita superfície de contato entre a realidade e a língua. O discurso constitui-se em práticas e, para defini-lo, é necessário buscar a lei das enunciações diversas e o lugar de onde elas vêm.

Ao analisarmos os discursos na comunidade Tradutores/Intérpretes BR, podemos observar que o discurso do sujeito tradutor tecnológico anuncia que, com a ferramenta digital, o tradutor/intérprete pode dizer aquilo que antes lhe era proibido ou aquilo que podia ser dito apenas por tradutores de renomada autoridade. Ao postar seus comentários, pode-se concordar, criticar e até mesmo polemizar sobre diversas questões em tempo real, tornando-se um sujeito "livre", que tem a ilusão de ser dono do seu discurso.

Nesses discursos, podemos constatar a idéia de Bauman (2001) de que vivemos a "modernidade líquida" e de que "ordem e caos" (BAUMAN, 1999, p. 12) fazem parte de um mesmo processo.

A ordem é o contrário do caos: este é o contrário daquela. Ordem e caos são gêmeos modernos. Foram concebidos em meio à ruptura e colapso do mundo ordenado e ao modo divino, que não conhecia a necessidade nem o acaso, um mundo que apenas era, sem pensar jamais em como ser.

O orkut surge como um grande representante de uma "nova" ordem e caos, pois o espaço digital cultua a liberdade de expressão e de leitura, de dizer o que quiser, onde e quando quiser, em tempo real. Trata-se de um preenchimento de uma crise existencial que evidencia a vontade de falar sem seguir uma ordem discursiva pré-estabelecida na qual o sujeito pode sentir-se livre.

Mas, podemos também identificar a ordem na própria estrutura e construção lingüística do orkut, porque para que o sujeito pertença a esse espaço digital, ele deve ser detentor da cultura da rede, dos seus códigos, protocolos e linguagens.

Portanto, como o sujeito constitui-se em suas práticas discursivas (FOUCAULT, 1987), temos no sujeito do orkut alguém mutifacetado, fragmentado e em constante conflito em meio à ordem e ao caos que o cercam, que se utiliza dessas redes como uma "técnica de si”" profissional e social, lazer, entre outros.

O sujeito tradutor/intérprete da comunidade analisada parece encontrarse numa encruzilhada, pois não há um lugar "do profissional de tradução" estabelecido dentro da sociedade - ele encontra-se na mesma situação do jornalista que luta por um espaço delimitado, ou seja, pelo reconhecimento de 
sua profissão. A faculdade de Letras acaba por ser citada e é uma marca discursiva da grande área do conhecimento.

Outro confronto estabelecido é a valoração da experiência em relação àquela do estudo acadêmico na formação do profissional. Assim, o sujeito tradutor/intérprete expõe sua angústia diante de uma realidade que não é nova: o discurso do reconhecimento da profissão ${ }^{\lceil 26]}$, defendido por uns e criticado por outros, porém, na web há a possibilidade de o sujeito estar mais visível e exposto do que em qualquer outro suporte. Dessa forma, tem-se o sujeito desejante, clivado, multifacetado na busca de ser alguém reconhecido socialmente por sua profissão e, portanto, ocupar um lugar de status dentro da sociedade por seu valor profissional e, algumas vezes, acadêmico.

Concorda-se com Coracini (2007, p.180), que afirma que o lugar do tradutor/ intérprete é de “instabilidade e de conflitos, ser tradutor parece significar um saber operar com sentidos que se cruzam, provenientes de várias regiões de discurso [...] lugar onde o que parece determinado é, na verdade, fluido e inseguro, sem pontos de fechamento e estabilidade". Sendo assim, para o bom profissional de tradução/interpretação, o seu lugar não é só da experiência ou da academia, mas a junção de ambos.

\section{Considerações Finais}

No mundo virtual, o sujeito tradutor/intérprete pode multiplicar seus contatos sociais sem deixar marcas de sua identidade, pode manipular sua identidade virtual adequando-se ao discurso de outros sujeitos virtuais, pode transformar-se em outro(s), o que não aconteceria no mundo real. Então, o sujeito do orkut experimenta a sensação de ser livre, quando na verdade participa de uma sociedade controladora e está preso à ordem discursiva dessa sociedade. Logo, a comunidade de Tradutores/Intérpretes BR funciona como um “arquivo", uma “técnica de si” ou, como diz Foucault (2004), encontra-se regida por uma lei do que pode ser dito, e seus enunciados surgem como acontecimentos singulares, inclusive a identidade do profissional tradutor/intérprete. Tal lei apresenta-se como democrática, libertária da regras acadêmicas, em que o profissional inserido no mundo tecnológico não precisa sabê-las nem segui-las, basta apenas que demonstre conhecimento empírico e prático da tradução.

As práticas discursivas e identitárias dentro da comunidade expõem toda a angústia de um sujeito desejante por estabelecer um lugar e um status de 'profissional de tradução e interpretação' reconhecido e valorizado pela sociedade. Assim, o orkut deixa de ser apenas uma rede digital de socialização para ser um importante espaço de prática discursiva, um instrumento de marketing, um lugar em que ele pode criar simulacros identitários e ganhar 
visibilidade dentro do mercado e junto à comunidade.

\section{Referências}

BAUDRILLARD, Jean. Simulacros e Simulação. Lisboa: Antropos, 1981.

Tela Total: mito-ironias da era do virtual e da imagem. Tradução de Juremir Machao da Silva. Porto Alegre: Sulina, 2005.

BAUMAN, Zygmunt. Tempos Líqüidos. Tradução Carlos Alberto Medeiros. Rio de Janeiro: Zahar, 2007.

. Modernidade e ambivalência. Rio de Janeiro: Jorge Zahar Ed,

1999.

. Modernidade líquida. Rio de Janeiro: Jorge Zahar Editor, 2001

CÉBRIAN, Juan Luis. A rede. São Paulo: Summus, 1999.

CORACINI, Maria José. A Celebração do Outro: arquivo, memória e identidade línguas (materna e estrangeira), plurilingüismo e tradução. 1a. ed. Campinas: Mercado de Letras, 2007.

FOLHA ONLINE. Orkut não entende seu sucesso no Brasil. 03 jul 2005. Disponível em <http://www1.folha.uol.com.br/folha/dinheiro/ult91u97858.shtml>. Acesso em 10 out 2007.

FOUCAULT, Michel. A arqueologia do saber. Tradução de Luiz Felipe Baeta Neves. São Paulo: Forense, 2004.

. O nascimento da clínica: a arqueologia do saber médico. Rio de Janeiro: Forense Universitária, 2004a) . A ordem do discurso. São Paulo: Loyola, 2005.

As palavras e as coisas: a arqueologia das ciências humanas.

São Paulo: Martins Fontes, 1987

GREGOLIN, M. R. V. Foucault e Pêcheux na análise do discurso: diálogos e duelos. São Carlos: Claraluz, 2007.

Michel Foucault: o discurso nas tramas da história. In: FERNANDES, Cleudemar Alves e SANTOS, João Bosco Cabral dos (Orgs.). Análise do Discurso: unidade e dispersão. Uberlândia: EntreMeios, 2004. p. 19-42.

GUILHAUMOU, J. \& MALDIDIER, D. Efeitos do Arquivo. A análise do discurso no lado da história. In: ORLANDI, E. (org.) Gestos de Leitura: da História no Discurso. Campinas: Editora da Unicamp, 1994.

LEMOS, André. Cibercultura: tecnologia e vida social na cultura contemporânea. Porto Alegre: Sulina. 2a ed., 2004

NAVARRO-BARBOSA, Pedro Luis. O acontecimento discursivo e a construção da identidade na história. In: SARGENTINI, Vanice; NAVARRO-BARBOSA, Pedro Luis (orgs.). Michel Foucault $e$ os domínios da linguagem - discurso, poder, subjetividade. São Carlos: Claraluz, 2004, p. 97-130

NOGUEIRA, Marcos. Orkut!. Revista Super Interessante, São Paulo, ano 19, n. 9, p. 80-87, setembro de 2004.

NOGUEIRA, Tânia; TERMERO, Maíra; LEAL, Renata. Festa brasileira na rede. Revista Época, São Paulo, n. 326, p. 96 - 102, 16 de agosto de 2004.

PÊCHEUX, Michel. O discurso: estrutura ou acontecimento. Campinas: Pontes Editores, 2006.

REVEL, Judith. Foucault: conceitos essenciais. São Carlos: Claraluz, 2005

SARGENTINI, Vanice M. O. A descontinuidade da história: a emergência dos sujeitos no arquivo. In: SARGENTINI, Vanice; NAVARRO-BARBOSA, Pedro Luis (orgs.). Michel Foucault $e$ os domínios da linguagem - discurso, poder, subjetividade. São Carlos: Claraluz, 2004, p. 77-96 
Utilizamos as palavras "novo" e "nova" entre aspas com o sentido de (re)significação, uma vez que para a análise de discurso francesa nenhum discurso é novo, original, sempre há um já dito, um já lá, um repetível, determinando os deslocamentos promovidos pelo sujeito nas fronteiras de uma formação discursiva (interdiscurso). No entanto esse já dito, esse já lá nunca é repetido da mesma maneira, portanto carrega em si (re)significações.

[2]

O próprio site se autodenomina rede digital, rede social, rede de relacionamento, rede de amigos ou comunidade online. Disponível em: <http://www.orkut.com.br/About.aspx>. Acesso em: 20 abr. 2008.

[3]

O conceito de socialização utilizado nesta pesquisa encontra-se em BAUMAN, Z. Ética pós-moderna. São Paulo: Paulus, 1997, p.1328. O autor afima que "A socialização (pelo menos na sociedade moderna) visa a criar um ambiente de ação feito de escolhas passíveis de serem 'desempenhadas discursivamente', que se concentra no cálculo racional de ganhos e perdas"

[4]

Em comunidades moderadas, o mediador é o encarregado de analisar o conteúdo das mensagens a serem postadas e de tomar qualquer tipo de decisão, até mesmo banir membros da comunidade.

[5]

Disponível em:< http://www.orkut.com/Community.aspx?cmm=50302>. Acesso em: 08 out. 2008.

[6] Disponível em: <http://www.orkut.com/Community.aspx?cmm=50302>. Acesso em: 08 out. 2008.

[7]

Orkut Buyukkokten nasceu na Turquia, onde estudou na renomada Bilkent University, em Ankara.

Possui pós-doutorado em ciência da computação na Stanford University, nos Estados Unidos, e desenvolveu o embrião do site nos bancos da universidade californiana, até ser contratado pela empresa de seus ex-colegas Sergey Brin e Larry Page. Disponível em: <http://www1.folha.uol.com.br/folha/dinheiro/ult91u97858.shtml>. Acesso em: 16 jun 2008.

[8]

Disponível em:<http://vidageek.net/2007/04/13/palestra-do-orkut/>. Acesso 15 abr. 2008.

[9] No início, era necessário receber um convite para ingressar no orkut, prática que foi substituída pela criação de uma conta no Google.

[10] "É proibida a participação de menores de 18 anos no orkut", essa informação encontra-se nos "Termos de Uso" e deve ser lida e confirmada pelo usuário antes de sua adesão.

[11] Disponível em: <http://www.orkut.com.br/Main\# MembersAll.aspx>. Acesso em: 08 out. 2008.

[12] Dados fornecidos pelo Núcleo de Pesquisa, Estudos e Formação (Nupef) da organização nãogovernamental Rede de Informações para o Terceiro Setor (Rits). Disponível em: <http://www.estadao.com.br/tecnologia/not_tec50368,0.htm>. Acesso em: 14 abr. 2008. [13]

Disponível em:<http://www1.folha.uol.com.br/folha/dinheiro/ult91u97858.shtml>. Acesso em: 14 de abr. 2008.

[14] Disponível em:<http://www.orkut.com.br/Main\#MembersAll.aspx>. Acesso em: 08 out. 2008.

[15] A atividade genealógica requer a busca da singularidade dos acontecimentos, sobretudo naquilo que não participa da história, como "[...] os sentimentos, o amor, a consciência, os instintos" (FOUCAULT, 2004 p. 260), fazendo emergir o entendimento sobre os espaços onde desempenharam papéis distintos e/ou foram excluídos do discurso verdadeiro.

[16]

Para Baudrillard (1981, p.22), “A simulação já não é a simulação de um território, de um ser referencial, de uma substância. É a geração pelos modelos de um real sem origem nem realidade: hiper-real".

[17] Para Bauman (2001) estamos passando por um processo de "liquefação" das estruturas e instituições sociais, ou seja, passando da fase "sólida" para a fase "fluida". A chamada "Modernidade Líquida" e os fluidos são assim chamados, pois não conseguem manter a forma por muito tempo, continuam mudando sob influência das menores forças.

[18]

Disponível em:

$<$ http://www.orkut.com.br/Main\#CommPollResults.aspx? $\mathrm{cmm}=50302 \&$ pct $=1221760924 \&$ pid=375610101>. Acesso em: 13 maio 2008 .

[19] Disponível em:

$<$ http://www.orkut.com.br/Main\#CommPollResults.aspx? $\mathrm{cmm}=50302 \&$ pct $=1219255848 \&$ pid $=1831217577>$. Acesso em: 13 maio 2008 .

[20]

Disponível em:

<http://www.orkut.com.br/Main\#CommPollResults.aspx? $\mathrm{cmm}=50302 \& \mathrm{pct}=1214143610 \& \mathrm{pid}=1869988741>$. Acesso em: 13 maio 2008 .

[21]

Disponível em: 

$\mathrm{cmm}=50302 \& \mathrm{pct}=1210075042 \& \mathrm{pid}=1083836377$ >. Acesso em: 13 maio 2008 .

[22]

A atuação do profissional tradutor e intérprete no mercado de trabalho não requer formação acadêmica.

[23]

Termo de origem inglesa (Frequently Asked Questions) que é uma compliação das perguntas freqüentes acerca de um determinado assunto.

[24] Disponível

em:

<http://www.orkut.com.br/CommMsgs.aspx? $\mathrm{cmm}=50302 \& \mathrm{tid}=2555091529895559656>$. Acesso em: 20 abr. 2008.

[25]

A expressão "técnica de si" ou "cuidado de si" utilizada por Foucault é "uma retomada do epimeleia beautou que se encontra, em particular, no Primeiro Alcebíades, de Platão, indica o conjunto das experiências e das técnicas que o sujeito elabora e que o ajuda a transformar-se a si mesmo." (REVEL, 2005)

[26]

A discussão sobre a regulamentação da profissão de tradutor existe desde 1970, com um projeto de lei apresentado ao Congresso Nacional que nunca foi aprovado. Apenas os Tradutores Públicos e Intérpretes Comerciais, conhecidos como Tradutores Juramentados, possuem regulamentação de sua área de atuação, sob o Decreto 13.609 de 21 de outubro de 1943, assinado por Getúlio Vargas. 